\title{
2. Historical Background
}

Makek M: Clinical Pathology of Fibro-Osteo-Cemental Lesions in the Cranio-Facial and Jaw Bones. Basel, Karger, 1983, pp 3-7

Our present understanding of the concept offibro-osteo-cementallesions is the result of many years of treatment and observation. The process can be said to have its origins both in the individual observations of such surgeons as Syme [1828], Maisonneuve [1856], Ferguson [1865], Menzel [1872] (fig. 1), Bryant [1874] etc., andin 1ater synop- tic works such as those by Hyfelder [1857], Weber [1866], Bayer [1884], and Kentenich [1896].

These were later followed by the first at- tempts to consider the clinically observed phenomena from a morphologica1 point of view. In 1864 , for example, Virchow intro- duced the term 'leontiasis ossea' to describe diffuse en1argements of the maxillo-facial bones. He chose this term because he had observed that patients suffering from 'hyper- ostosis' often had a monstrous, almost leo- nine facial appearance, similar to that ob- served in cases of leprous leontiasis. Though undoubtedly useful, Virchow's work could not claim the distinction ofhaving character- ized an etiologically defined pathological en- tity.

A breakthrough in the field of osteopatho- logy was made by Pagetin 1877, when he defined the clinical and pathological charac- teristics of an entity which he called 'osteitis deformans'. Though largely ignored on the 
Continent, this entity gained rapid recogni- tion in Britain. One of the main reasons for the Europeans' initial unwillingness to accept 


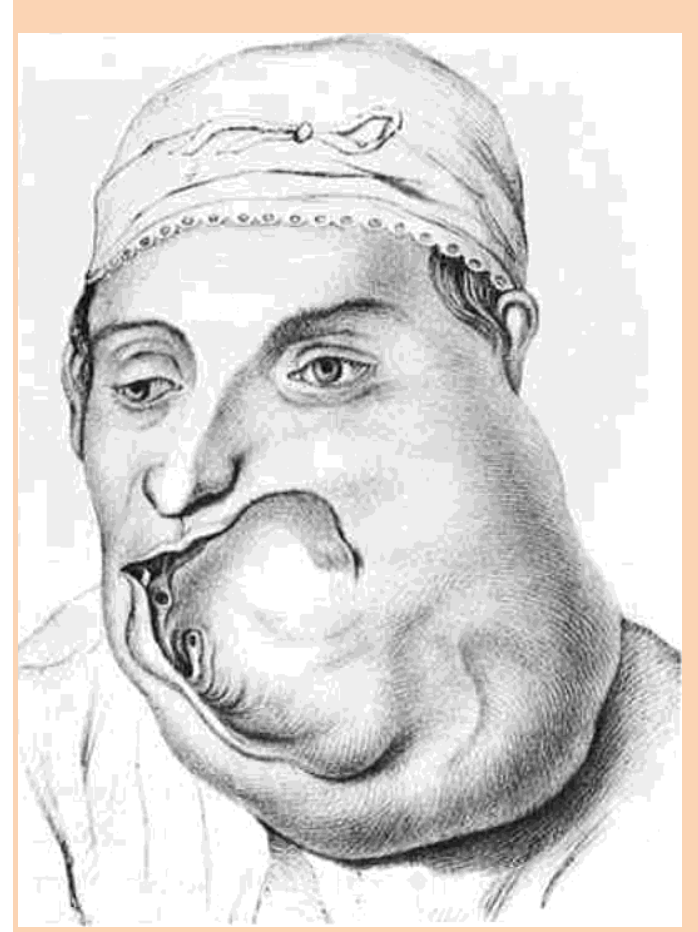

Fig. I. 35-year-old woman with osteofibroma operated on by A. Menzel (Vienna, 1870). The tumor had been growing for more than 25 years [from Men- zel, 1872].

Paget's findings is undoubtedly the diverging approach taken by Friedrich Daniel von Reckfinghausen (fig. 2). His monumental work was dedicated to Rudolf Virchow and was published on the 13th of October 1891, to mark the occasion of the latter's 70th birthday. In his treatise, von Reckfinghausen 


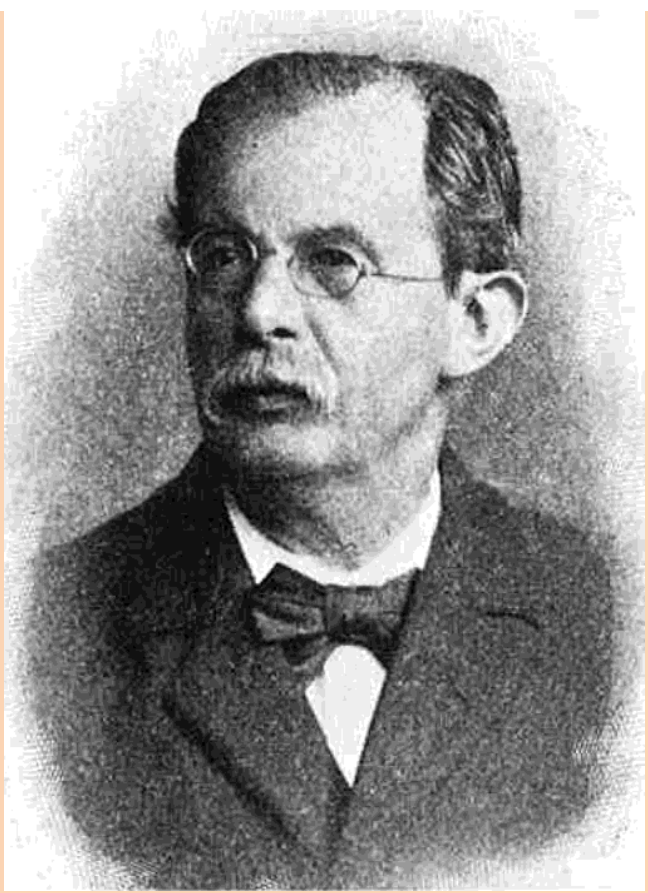

Fig. 2. Friedrich Daniel von Reckfinghausen (1833-1910).

[1891] introduces the term 'osteitis fibrosa', and applies it to all the cases of skeletal lesions he had observed where the bone mar- row was either partially or totally trans- formed into fibrous tissue. This would of course include those cases whose fundamen- tal morphology is identical to that of Paget's disease. Christeller [1926] speaking to a meeting of the Deutsche Gesellschaft für Pa- thologie, put forward this unitarist point of view as late as 1926, though he did differen- tiale between two forms of 'osteitis fibrosa'. 
One was hyperostotic and could in fact be taken to correspond to Paget's disease, while the other was hypostotic and corresponded to 'osteodystrophia fibrosa'. On the very same day, Schmor! [1926] who was also present, 
managed to produce empirical proof that these two bone lesions were not only clini- cally different, but that they were also funda- mentally dissimilar both from a pathological and an anatomical point of view. His find- ings were based on 25 autopsy cases. In the same year, the unitarist approachwas refuted for once and for all by findings made by Mandl [1926]. He was the first person to suc- ceed in removing an adenoma ofthe parathy- roid gland from a patient with osteitis fibrosa generalisata, thus contributing substantially to a better understanding of this systemic bone lesion. This newly developed parathy- roid gland surgery could thus be used in con- junction with chemical and physiological ex-aminations to isolate the syndrome ofhyper- parathyroidism. These investigations made it possible to isolate this syndrome conclu- sively and also to establish that it was (a) characteristic of osteitis fibrosa generalisata, and (b) in no way related to Paget's osteitis deformans. This, however, was but a first step. It soon emerged that a number of condi- tions, which should in fact have been classi- fied in a separate group of their own, were often being diagnosedas 'osteitis fibrosa gen- eralisata'. Indeed, if one looks through old case histories or old medical journals, one occasionally comes across cases which are described as 'atypical Recklinghausen', 'doubtful Recklinghausen', 'Recklinghaus- en's localized fibrocytic osteitis' or 'Reck- linghausen without lesion in the parathyroid gland'. Faced with this muddled terminolo- gy, Konjetzny [1922] introduced the term 'os- teitis fibrosa 
localisata', with a view to distin- guishing localized processes featuring fibrous bone transformation from more generalized alterations. However, since this resulted in the most diverse bone lesions being diag- nosed either as 'osteitis fibrosa localisata' or

'osteitis fibrosa generalisata' merely accord- ing to whether they occurred generally or locally, Konjetzny hirnself soon decided to reject this definition. Montgomery [1927] was the first to use the term 'ossifying fibroma'. He used this term to denote those tumoraus conditions occurring in the maxillo-facial bones which were sharply delineated and featured fibrosis and a degree of new bone formation. He describes 3 cases of his own and cites a fur- ther 14 cases drawn from the literature which he regards as similar.

laffe [1933] described a number of cases

of osteitis fibrosa cystica which were remark- able in that they did not feature tumors ofthe parathyroid gland. He suggested that these cases were not classifiable either as Reck-

1inghausen's bone disease or as Paget's dis- ease, and that they should be regarded as a third and separate condition which had yet to be described in greater detail. At the time, he assumed that these conditions were of con- genital origin. 
Stafne [1933] described the radiological and clinica1 characteristics of 35 cases of ce- menta11esions in the jawbones. Stafne [1934] went on to describe what he termed 'periapi- ca1 osteofibrosis', a condition which is char- acterized, histologically, by the simultaneaus formation of new bone and fibrous tissue. In

1937, Thoma described a number of cases of cementoblastoma of the maxillo-facial bones, dividing their development into three distinct stages. In the same year, Phemister and Grimson [1937] published a study of 13 cases which they regarded as typically characteristic of 'fibrous osteoma'. In addition to these, their study also reevaluated two of Montgomery's [1927] cases and cited a fur- ther 30 drawn from the literature. The au- thors formulated the hypothesis that the rela- 


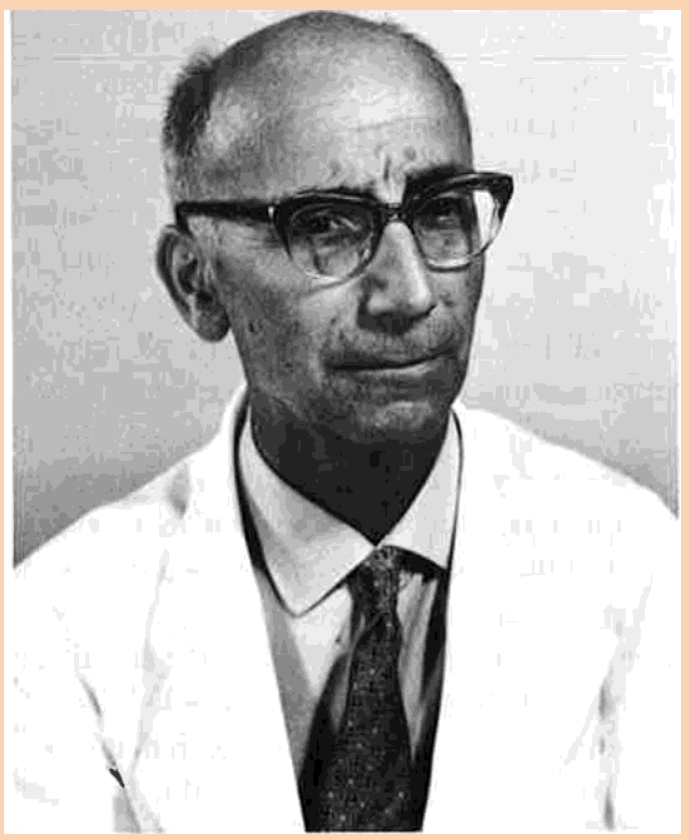

Fig. 3. Erwin Uehlinger (1899-1980).

tionship between 'fibrous osteoma' and the desmal bones was analogaus to that already observed between osteochondroma and the hyaline bones. They also considered the pos- sibility that compact osteoma might in fact be the final stage in the development of 'fi- bro-osteoma'. Albright et al. [1937] published a study dealing with five cases of a bone lesion which was characterized by osteitis fibrosa disseminata, large patches of abnor- mal 
skin pigmentation and endocrine dys- function accompanied by pubertas praecox. Lichtenstein [1938] described the characteris- tics of another condition which he termed 'polyostotic fibrous dysplasia'. A detailed and comprehensive comparison between the skeletal alterations associated with the condi-

tion described by Atbright et al. [1937] and those which characterize 'fibrous dysplasia' as described by Lichtenstein [1938] shows that the two are absolutely identical. Both authors have observed exactly the same alterations to the bones ofthejaw and sku11. Eden [1939] published a study covering a number of cases of maxillo-facia1 bone lesions in which he concluded that 'ossifying fibroma' was in fact an immature form of 'benign fibro-osseous tumor ofthe membrane bone'.

Uehlinger [1940] (fig. 3) published what is undoubtedly the most significant study of fibrous dysplasia to be written in German. He was the first to publish findings based on autopsy material secured from a patient with fibrous dysplasia. He described the condition as 'osteofibrosis deformans juvenilis'. One of the most important findings which this au- topsy produced was that it was able to prove that the hypothalamus and the parathyroid g1and were normal. 
Lichtenstein and laffe [1942] again de- scribed the clinical, radiological and histolog- ical characteristics of fibrous dysplasia, in a new study based on an expanded body of case material which now comprised 24 cases. Thus, by the early 1940s, it was already apparent that von Recklinghausen's [1891] term 'osteitis fibrosa' would have to be di- vided into three quite distinct pathological entities. These were: osteitis deformans Pa-get, osteodystrophia fibrosa generalisata (pri- mary and secondary hyperparathyroidism) and fibrous dysplasia in both its monostotic and polyostotic forms. Concerning the latter, it should be noted that the possibility of polyostotic forms of fibrous dysplasia also being accompanied by endocrinal disorders (Albright's syndrome) had also been recog- nized. All these alterations are known to oc- cur in the bones of the jaw and skull. 
Besides the three already mentioned (Pa-get's disease, Recklinghausen's bone disease and fibrous dysplasia), other tumoraus enti- ties, suchascementoblastoma [Thoma, 1937], ossifying fibroma [Montgomery, 1927] and fibro-osteoma [Phemister and Grimson, 1937], had already been isolated by that time and were also known in the literature. Repa- rative alterations of the maxillofacial bones had also been recognized as such, and had been diagnosed as chronic, hypertrophic, nonpurulent Osteomyelitis [Axhausen, 1934].

Because of the morphological similarity be- tween this condition and Paget's disease, $A x$ - hausen [1934] uses the term 'pseudo-Paget'.

Regrettably, this process of p1ura1istic dif- ferentiation ofthese conditions then more or less came to a halt. In fact, subsequent work carried out in this field tended towards a more unitarist view. No sooner had the term 'fibrous dysplasia' been introduced as an entity, than a who1e series of authors began to voice the assumption that ossifying fibroma and fibrous dysplasia were closely related. A study by laffe and Lichtenstein published as early as 1942 regarded the characteristics of several cases presented by Phemister and Grimson [1937] as indistinguishable from those associated with fibrous dysp1asia. It was in the same year, 1942, that Mallory con- jectured that fibro-osteoma and fibrous dys- plasia were in fact one and the same entity. Sehtumberger [1946a] published a study of 
67 cases of monostotic fibrous dysplasia in which he put forward the view that 'ossifying fibroma' and 'nonossifying fibroma' of the bone were nothing other than two versions of one single entity, namely fibrous dysplasia. In a second study, Sehtumberger [1946b] made one of the first attempts to classify all the various fibro-osseous lesions of the bone as different versions ofthe same pathological

process. Mammel [1948], in his histological study of ossifying fibroma and fibrous dys- plasia, concurs with Sehtumberger [1946b] on this point. Over the past 30 years, this unitarist approach has resulted in the generic term 'fibro- osseous lesions of the maxillo-facial bones' being evolved [Berger and Jaffe, 1953; Cooke, 1957; Hamner et al., 1968; Panders, 1970; Waldron, 1970; Schmaman et al., 1970; Cangiano et al., 1971; Meisteret al., 
1973; Waldran and Giansanti, 1973a, b;

Abrams and Me/rose, 1975; Boysen et al.,

1979]. It has been used to cover not on1y tumors (osteofibroma, ossifying fibroma, ce- mentifying fibroma), but also inflammatory and reparative processes (pseudo-Paget, peri- ostitis ossificans Garre), dysplastic alterations (fibrous dysplasia) and even some con- ditions whose etiological characteristics are unclear (Paget's disease, periapical cemental dysplasia). 